\title{
Comparative Study of Sympathetic Activity in Normotensive Obese and Nonobese Adults
}

\author{
Syeda Samina ${ }^{1}$, Mohammed Mazhar ul Haque ${ }^{2}$ \\ ${ }^{l}$ Assistant Professor of Physiology, Great Eastern Medical School \& Hospital, Ragolu, Srikakulam, Andhra \\ Pradesh, ${ }^{2}$ Professor of Anaesthesia, Patnam Mahender Reddy Institute of Medical Sciences, Chevella, Telangana
}

\begin{abstract}
Aim: The aim of the study is to assess sympathetic activity in Obese Normotensive subjects

Objectives: To investigate any changes in sympathetic activity in Normotensive obese subjects using Cold Pressor test

Method: 50 Obese subjects of both genders between age group $18-25$ years with $\mathrm{BMI}>25 \mathrm{~kg} / \mathrm{m}^{2}$ were selected as study group and 50 age matched subjects of both the genders with $\mathrm{BMI}<25 \mathrm{Kg} / \mathrm{m}^{2}$ were selected as control group. Sympathetic activity was assessed using Cold pressor test. In this test, After recording the resting blood pressure (BP), the subject was asked to immerse his hand in cold water (temperature maintained between $5^{\circ}-9^{\circ} \mathrm{C}$ ). BP measurement from other arm was done at $30 \mathrm{sec}$ interval for two minutes using continuous ambulatory Blood pressure monitoring, after which the subject was asked to remove the hand from cold water. Maximum increase in Diastolic Blood Pressure (DBP) was taken as test response.

Results: Statistical analysis was done using unpaired t test.Increase in diastolic blood pressure with Cold pressor test in study group was significantly increased compared to control group.

Conclusion: Increased sympathetic activity is seen in obese normotensive subjects, which is a risk factor for future development of hypertension and other complications associated with increased sympathetic activity.weight loss and maintanence of healthy lifestyle is suggested to the subjects to prevent the future complications.
\end{abstract}

Keywords: Normotensive Obese, Cold pressor test, sympathetic activity, Diastolic blood pressure.

\section{Introduction}

Obesity, considered a worldwide epidemic, is characterized by the excessive accumulation of fat tissue in the body and its causes are multifactorial, such as genetic susceptibility, sex, age, occupation, diet and others ${ }^{1}$. It is well recognized that obesity is associated with reduced quality of life and increased risk

\section{Corresponding Author:}

\section{Dr. Mohammed Mazhar ul Haque}

Professor of Anaesthesia, Patnam Mahender Reddy Institute of Medical Sciences, Chevella, Telangana e-mail:drmnhaq@gmail.com of premature death and predisposes individuals to the development of a number of chronic illnesses including cardiovascular disease, type 2 diabetes, dyslipidemia, insulin resistance, hyperglycemia, hypertension, degenerative joint diseases, obstructive sleep apnea (OSA), gastroesophageal reflux disease, nonalcoholic fatty liver, and various forms of cancer ${ }^{2}$.

Obesity and its early complications (i.e. insulin resistance and impaired fasting glucose) are associated with overstimulation of the sympathetic nervous system (SNS) and decreased tone of the parasympathetic nervous system (PNS) ${ }^{3}$

Studies using norepinephrine urinary excretion and plasma concentration measurements from hypothalamic 
models of obesity show that sympathetic nervous activity in obesity is low ${ }^{4}$. Young and Macdonald ${ }^{5}$ found that there were numerous studies proposing that Sympathetic nervous system (SNS) in subjects with obesity was either low, normal, or elevated. The heterogeneity of the results most likely occurred because of inadequacy of the method used (in particular, venous or urinary norepinephrine concentrations) and because SNS activity is typically regionalized, where the efferent outflow throughout the body is not uniform.

Studies have also shown that SNS activation may be responsible for development of obesity. Increased plasma norepinephrine concentration and a hyperkinetic circulation in young adulthood have been shown to predict future weight gain and the development of insulin resistance ${ }^{6}$.

The present study is carried out to evaluate the sympathetic activity in Obese subjects.

\section{Materials and Method}

The study was carried out at Great Eastern Medical school, Srikakulam, Andhra Paradesh

Study Group: 50 Obese subjects of both genders between age group $18-25$ years with $\mathrm{BMI}>25 \mathrm{~kg} / \mathrm{m}^{2}$ were selected as study group

Control Group: 50 Nonobese subjects of both genders between age group 18-25 years with $\mathrm{BMI}<25 \mathrm{~kg} /$ $\mathrm{m}^{2}$ were selected as control group

Inclusion criteria for study group:

1. $\quad \mathrm{BMI}>25 \mathrm{~kg} / \mathrm{m}^{2}$

2. Normotensive subjects

\section{Inclusion criteria for control group:}

1. $\mathrm{BMI}<25 \mathrm{Kg} / \mathrm{m}^{2}$

2. Normotensive subjects
Exclusion criteria (common for study and control group):

1. Hypertensive subjects

2. Diabetic subjects

3. Any history of chronic illness

All the subjects were explained about the test to assess sympathetic function and an informed consent was taken.

Sympathetic activity was assessed by cold pressor test.

Cold pressor test (CPT): After recording the resting blood pressure (BP), the subject was asked to immerse his hand in cold water (temperature maintained between $5^{\circ}-9^{\circ} \mathrm{C}$ ). BP measurement from other arm was done at $30 \mathrm{sec}$ interval for two minutes using continuous ambulatory Blood pressure monitoring, after which the subject was asked to remove the hand from cold water. Maximum increase in Diastolic Blood Pressure (DBP) was taken as test response.

Somatosensory stimulation induced by the cold stimulus increases blood pressure; impulses from receptors in the skin relay via afferent pathways to $\mathrm{C} 1$ cells in the rostral ventrolateral (RVL) reticular nucleus and are transmitted via efferent sympathetic neurons to peripheral blood vessels from thoracic spinal cord. Thus, somatosensory stimulation produces the pressor response during the cold pressor test.

\section{Statistical analysis:}

Statistical analysis was done using unpaired $t$ test

$\mathrm{P}$ value $<0.05$ was considered as statistically significant

The results were expressed as Mean \pm standard deviation

Finding:

\begin{tabular}{|l|c|c|c|c|c|}
\hline \multirow{2}{*}{ Variable } & \multicolumn{2}{|c|}{ Study Group } & \multicolumn{2}{|c|}{ Control Group } & \multirow{2}{*}{ P Value } \\
\cline { 2 - 5 } & Mean & SD & Mean & SD & \\
\hline Increase in DBP (mmHg) with Cold Pressor Test & 15.7 & 3.1 & 13.2 & 2.3 & $<0.0001^{*}$ \\
\hline
\end{tabular}


DBP-Diastolic blood pressure

On Analysis,

Increase in diastolic blood pressure with cold pressor test in study group was significantly increased compared to control group.

\section{Discussion}

In our study,we found that increase in Diastolic blood pressure with cold pressure in obese normotensive subjects was significantly increased compared to Nonobese normotensive subjects.

The findings of our study were in accordance with previous studies ${ }^{7}$ which showed increased sympathetic activity in obese normotensive subjects.

However some studies reported no change and even reduction in sympathetic activity in obese subjects ${ }^{8}$.

Obesity is characterized by excessive accumulation of fat, a highly dynamic endocrine and paracrine organ that releases many cytokines and bioactive mediators which may influence sympathetic nervous system activity ${ }^{9}$. While there exists a large body of evidence indicating that sympathetic nervous activity is evident in obesity, it is important to recognize that many factors may be involved in the genesis of obesity-related sympathetic activation ${ }^{10}$.

It is well established that obesity is one of the major determinants in the development of hypertension in the general population ${ }^{11}$. The mechanisms contributing to the development of higher blood pressure in humans with obesity include many factors such as hyperinsulinemia, activation of the renin-angiotensin-aldosterone system, abnormal levels of certain adipokines such as leptin, and an altered spectrum of cytokines acting at the vascular endothelial level ${ }^{12}$.

Sympathetic nervous stimulation is certainly a key factor in the development of hypertension. It was demonstrated than when weight gain develops in young men, increased Muscle Sympathetic Nerve Activity (MSNA) occurs early, together with increased blood pressure $^{13}$. It was shown that sympathetic activation to the kidneys occurs as early as $1 \mathrm{wk}$ after exposure to a high-fat diet in rabbits ${ }^{14}$.

\section{Conclusion}

Increased sympathetic activity is seen in obese normotensive subjects, which is a risk factor for future development of hypertension and other complications associated with increased sympathetic activity. Weight loss and maintanence of healthy lifestyle is suggested to the subjects to prevent the future complications.

\section{Source of Funding: Self}

Ethical Clearance: Taken from Scientific Ethical committee, Great Eastern Medical school, Srikakulam, Andhra Pradesh.

\section{Conflict of Interest: Nil}

\section{References}

1. McArdle WD, Katch FI, Katch VL. Essentials of exercise physiology. Philadelphia - USA. Lea \& Febiger; 1994

2. Key TJ, Schatzkin A, Willett WC, Allen NE, Spencer EA, Travis RC. Diet, nutrition and the prevention of cancer. Public Health Nutr 7: 187200, 2004.

3. Emdin M, Gastaldelli A, Muscelli E, Macerata A, Natali A, Camastra S \& Ferrannini E. Hyperinsulinemia and autonomic nervous system dysfunction in obesity: effects of weight loss. Circulation 2001103 513-519.

4. Spraul M, Ravussin E, Fontvieille AM, Rising R, Larson DE, Anderson EA. Reduced sympathetic nervous activity: a potential mechanism predisposing to body weight gain. J Clin Invest. 1993; 92: 1730-1735

5. Young JB, Macdonald IA. Sympathoadrenal activity in human obesity: heterogeneity of findings since 1980. Int J Obes Relat Metab Disord 16: 959967, 1992.

6. Masuo K, KawaguchiH, Mikami H, Ogihara T, Tuck ML. Serum uric acid and plasma norepinephrine concentrations predict subsequent weight gain and blood pressure elevation. Hypertension 42: 474 480, 2003

7. Guido Grassi, Gino Seravalle, Bianca M. Cattaneo. Sympathetic Activation in Obese Normotensive Subjects. Hypertension. 1995;25:560-563.

8. Peterson HR, Rothschild M, Weinberg CR, Fell $\mathrm{RD}$, Macleish KR, Pfeifer MA. Body fat and the activity of the autonomic nervous system. N Engl J Med.1988; 318:1077-1083.

9. Head GA, Lim K, Barzel B, Burke SL, Davern PJ. 
Central nervous system dysfunction in obesityinduced hypertension. Curr Hypertens Rep 16: 466, 2014.

10. Straznicky NE, Eikelis N, Lambert EA, Esler MD. Mediators of sympathetic activation in metabolic syndrome obesity. Curr Hypertens Rep 10: 440447, 2008.

11. Kannel WB. Fifty years of Framingham Study contributions to understanding hypertension. J Hum Hypertens 14: 83-90, 2000.

12. Hall JE, da Silva AA, do Carmo JM, Dubinion J, Hamza S, Munusamy S, Smith G, Stec DE.
Obesity-induced hypertension: role of sympathetic nervous system, leptin, and melanocortins. J Biol Chem 285: 17271-17276, 2010.

13. Gentile CL, Orr JS, Davy BM, Davy KP. Modest weight gain is associated with sympathetic neural activation in nonobese humans. Am J Physiol Regul Integr Comp Physiol 292: R1834-R1838, 2007.

14. Armitage JA, Burke SL, Prior LJ, Barzel B, Eikelis N, Lim K, Head GA. Rapid onset of renal sympathetic nerve activation in rabbits fed a highfat diet. Hypertension 60: 163-171, 2012. 